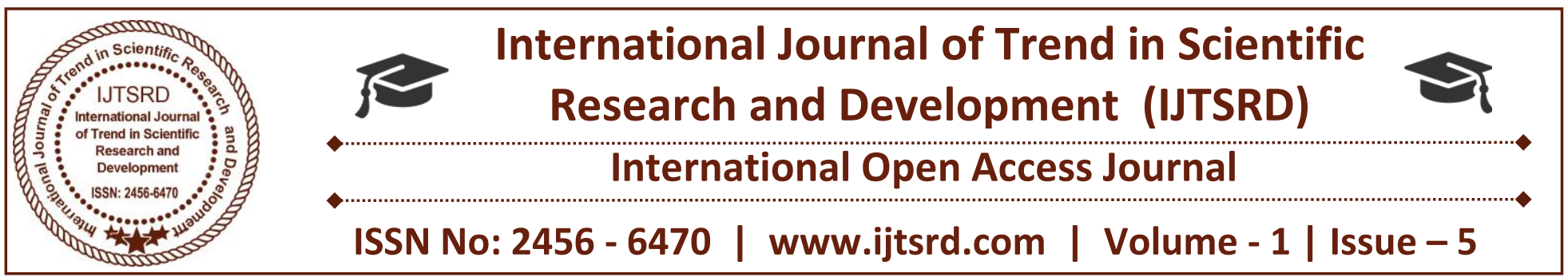

\title{
Recent Scenario of Solar Power Street Light(Spsl) with Auto-Intensity Control and How to Increase it Efficiency
}

\author{
Rizwan \\ Department of Electrical and Electronics Engg. \\ (EEE), AL-Falah University, Faridabad, India
}

\author{
Mohd Ilyas \\ Department of Electrical and Electronics Engg. \\ (EEE), AL-Falah University, Faridabad, India
}

\section{ABSTRACT}

Solar System has an abundant form of renewable energy which has potential to fulfill billions of watt of electricity. Now a day solar system is required to generate electricity due to sky rocketing price of oil, natural gas, coal. A solar lighting system which can make a 18x3 w lamp glow continuously for about (10) hours if the battery is fully charged has been constructed. Here, solar energy is collected with the aid of a solar panel and thus, a battery is charged during day time with the help of a simple charging circuit. At dusk, they turn on (usually automatically, although some of them include a switch for on, off and automatic) and remain illuminated overnight, depending on how much sunlight they receive during the day time. During night time, this stored energy is used to light. The device can be used for small-scale lighting applications in remote areas that are far away from the power grid. The system has a panel to collect the sun's energy, a battery to store that energy and a light source to use the energy. The system operates like a bank account. Withdrawals from the battery to power the light source must be compensated for by commensurate deposits of energy form the solar panels. The main objective is that LED Street lighting is a fresh new alternative to traditional street lamps such as LPS, HPS, or MH street lights.

\section{INTRODUCTION}

The Street lights are the major requirements in today's life for safety purposes and avoiding accidents during night. Providing street lighting is one of the most important and expensive responsibilities of a city.
Lighting can account for $12-35 \%$ of the total energy bill in typical cities worldwide. Street lighting is a particularly critical concern for public authorities in developing countries like India because of its strategic importance for economic and social stability. The fixtures of street lights indirectly have assisted the public and government in reduction of crime rate and accidents in the area.

The term "photovoltaic" comes from the Greek in which photo means "light", and "voltaic", means electric, from the name of the Italian physicist Volta, after whom a unit of electro-motive force, the volt, is named. The term "photo-voltaic" has been in use in English since 1849.

The photovoltaic effect was first recognized in 1839 by French physicist A. E. Becquerel. However, it was not until 1883 that the first solar cell was built, by Charles Frits, who coated the semiconductor selenium with an extremely thin layer of gold to form the junctions. The device was only around $1 \%$ efficient. Subsequently Russian physicist Alexander Stoletov built the first solar cell based on the outer photoelectric effect (discovered by Heinrich Hertz earlier in 1887). Albert Einstein explained the photoelectric effect in 1905 for which he received the Nobel Prize in Physics in 1921.Russell Ohl patented the modern junction semiconductor solar cell in1946, which was discovered while working on the series of advances that would lead to the transistor. 


\section{COMPONENTS OF SPSL}

1) Solar Panel

2) LED lamps

3) Rechargeable Battery

4) Light pole

5) Controller

6) Interconnecting cables

\section{SOLAR PANELS}

The solar panel or PV cell in the solar street light is one of the most essential parts. These cells are available in two types: mono crystalline and poly crystalline. The mono crystalline conversion rate is higher than the poly crystalline. The light energy used by the solar panels from the sun is used to change solar energy into electricity, which can be used in various applications.

Electrical connections of this project are made in series to achieve an o/p voltage and to afford a current facility connections are made in parallel. The majority of the modules use silicon ( $\mathrm{Si}$ ) but most of the solar panels are fixed.

\section{LIGHT EMITTING DIODE}

LEDs are used in modern street lights to provide brighter light with low energy consumption. The energy consumption of LED fixture is lesser than the high pressure sodium fixture, which is commonly used in traditional street lights. Compare to the other lamps, LED lights do not produce light in all directions. The design of lamps can be effected by the uniqueness of the LEDs. The single LED o/p is not equal to the incandescent and fluorescent lamps. But, a bunch of LEDs will give bright light than these two lamps. The advantages of LEDs mainly include Eco friendly, durable, zero UV emissions and long life.

\section{RECHARGEABLE BATTERY}

Rechargeable battery is a one kind of electrical battery and it has electro mechanical reactions to adjust so it is also called as secondary cell. Generally, there are two kinds of batteries, namely gel cell deep cycle and lead acid battery. A rechargeable battery is used in solar LED street lights, this battery is used to store electricity generated from the solar panel during the sunrise to afford energy in the sunset. The lifetime and capacity of the rechargeable battery are essential as they affect the backup power days of the lights.

\section{CONTROLLER}

A controller is a very significant device in solar street light, used to decide the status of the charging and lighting by switch on or switch off. Some recent controllers are pre programmed and it consists of a battery charger, a Led lamp driver, a driver, a secondary power supply, an MCU and a protection circuit. The battery can be controlled by the controller from the under and over charging conditions. The battery can be charged by the power received from the solar panels in the sunrise and while in the sunset it charges the battery.

\section{POLE}

A strong pole is mandatory for each and every street light and also for a solar street light. There are various components such as panels, batteries and fixtures fixed on the top of the pole. In this light, the $\mathrm{i} / \mathrm{p}$ operating voltage is $12 \mathrm{~V}$ DC which is a nominal system voltage, and the light o/p at the height of 12 feet is a minimum of 09 LUX (unit of luminance).

\section{INTERCONNECTING CABLES}

The cable is used to interconnect the LED, solar panel and battery box which is fixed on the top of the pole. This cable is used to connect a Photovoltaic module to the controller, controller to the lamps and battery. The size and length of the cable depend on the current being carried to the LED lights and the height of the pole. The assembling of the entire solar LED street light system can be connected using all the above components which use sun energy to give the power to the LED lamps fixed on street poles. 


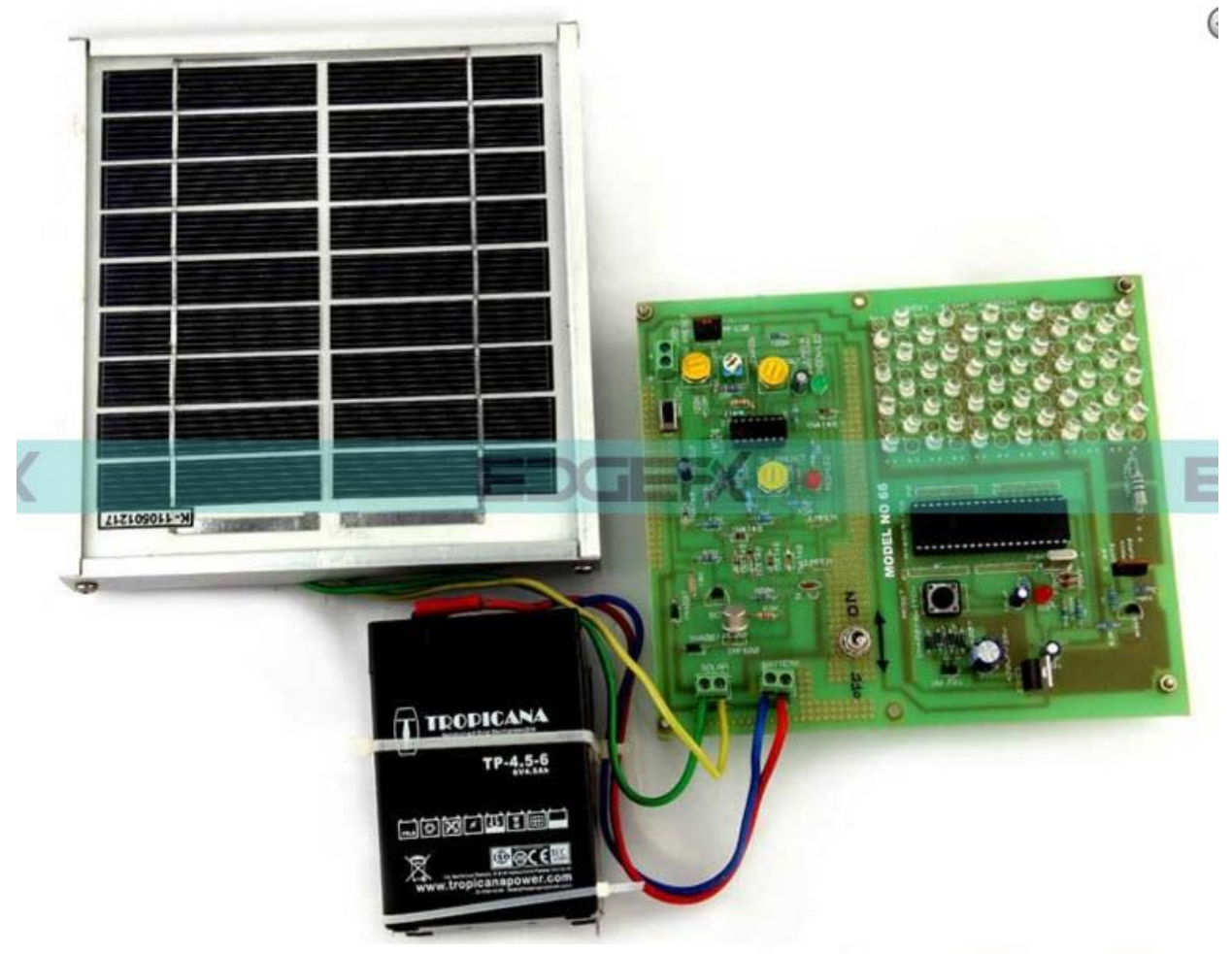

\section{Solar Powered Led Street Light with Auto Intensity Control}

Thus, this is all about Solar Powered Led Street Light with Auto Intensity Control. We hope that you have got a better understanding of this concept. Furthermore, any queries regarding this concept or electrical and electronic projects, please give your feedback in the comment section below. Here is a question for you, what is the function of a solar panel.

\section{WORKING OF SPSL:-}

A solar lamp is a portable light fixture composed of a LED lamp, photovoltaic solar panel, pole, connecting cable and a rechargeable battery. Solar lamps recharge during the day. At dusk, they turn on (usually automatically, although some of them include a switch for on, off and automatic) and remain illuminated overnight, depending on how much sunlight they receive during the day. Discharging time is generally 8 to 10 hours. Solar lights are easily installed and maintained, and provide a cheaper alternative to wired lamps. LED Street lighting is a fresh new alternative to traditional street lamps such as LPS, HPS, or MH street lights.

LED lighting provides a multitude of advantages over conventional incandescent light: LED street lights are environmentally friendly, energy efficient, and costeffective. This smart, "green" option for outdoor lighting has emerged on the green scene due to the recent technological advancements of LED illumination. But more "greener" option is Solar street lighting by recycled green energy lighting system. They are of energy saving and environmental friendly, which can be used for residential, road, park and so on. High quality solar panel absorbs sunlight and convert into electric energy, then charges maintenance-free battery and finally LED street lights automatically when day off, auto-off when day break. The working method of solar street lights is: solar panel absorbs sunlight and converts it to electricity to drive $12 \mathrm{~W} / 36 \mathrm{~W}$ LED Street light. The whole system is mainly composed by: 12W/36WLED street lighting, solar panel, lead acid battery and solar street lighting controller, pole (suggest 6-8m height). 

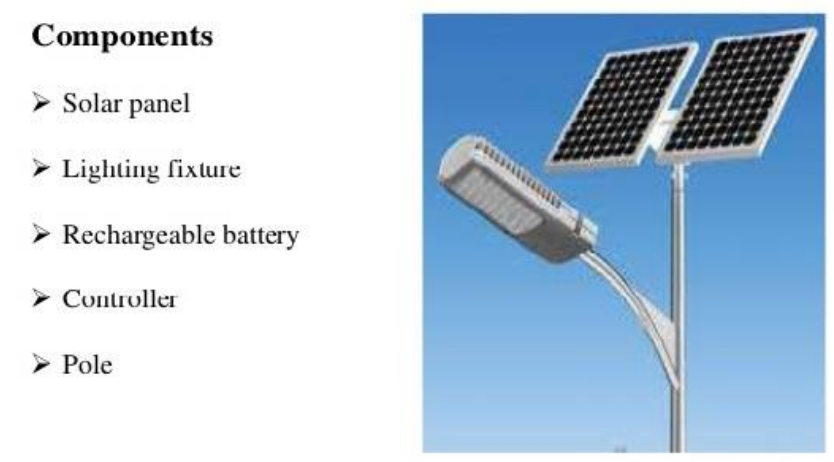

Solar Powered LED Street Light with Auto
Intensity Control

HOW TO INCREASE THE EFFICIENCY OF SPSL WITH AUTO INTENSITY CONTROL

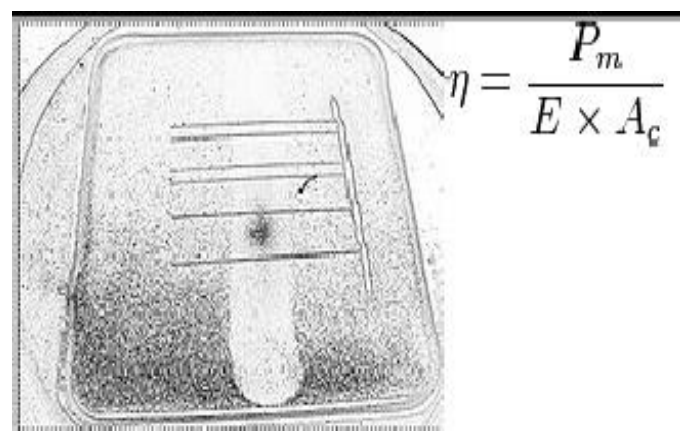

Dust often accumulates on the glass of solar panels seen here as black dots. A solar cell's energy conversion efficiency is the percentage of power converted (from absorbed light to electrical energy) and collected, when a solar cell is connected to an electrical circuit. This term is calculated using the ratio of the maximum power point ( $\mathrm{Pm}$ ), divided by the input light irradiance $(\mathrm{E}$, in $\mathrm{W} / \mathrm{m} 2)$ under standard test conditions (STC) and the surface area of the solar $\operatorname{cell}(\mathrm{Ac}$, in $\mathrm{m} 2)$.

1. Solar Power Street Light have an operating point at which the power produced is at its maximum and any movement away from this point will progressively decrease the efficiency of the panel. In order to extract all the energy that a solar panel is capable of delivering, a fully electronic system called the Max Peak Power Tracker (MPPT) is required. The MPPT is a DC-to-DC converter that poses as an optimum load, allowing the panel to operate at its peak-power state. Since the Max Peak Power Point (MPP) is dependent on the amount of radiant sunlight and temperature of the panel, the MPPT must constantly adapt to maximize the energy conversion.

2. We can increase the efficiency by minimizing the input light irradiance(E).

3. Efficiency can be increased by reducing the Surface area of the solar cell(Ac, in m2) which will also increase the intensity of light emitting.

4. High Brightness LEDs in today's scenario can be used to increase efficiency, low maintenance costs, and ability to produce a variety of color.

5. We can tilt the solar panel at an angle towards the sun from where maximum solar energy can be fetched from sunlight.

6. We can give the optimum gap between the two solar panel so that light emitting at night should not be overlapped much in order to optimize the no. of solar panels.

7. Height of the pole should be according to the solar panel so that it should get maximum amt. of sunlight.

8. Height of lamp should be 5-6 meters which in result intensity of light will be good on street.

9. We can use movable solar panel which will be sunlight sensitive to fetch maximum amount of sunlight.

10. We can use the optimized size of solar panel so that it will charge the battery fully in day time and can be utilized during night.

\section{ADVANTAGES}

1. Lower power consumption

2. Higher power, higher intensity

3. Save all your electricity cost. Save electric transformer and cable cost. Free maintenance

4. Environmental Impact - Eliminate Hazardous Disposal

5. Longer lifetime: Lifespan of solar panel is 20-25 years. Lifespan of LED street lights is 6-8 years. Lifespan of battery is 4-6 years.

6. Lower Operating Cost - It is less expensive to operate a solar powered street light than a traditional street light.

\section{DISADVANTAGES}

1. Initial investment is higher compared to conventional street lights.

2. Risk of theft is higher as equipment costs are comparatively higher. 
3. Snow or dust, combined with moisture can accumulate on horizontal PV-panels and reduce or even stop energy production.

4. Rechargeable batteries will need to be replaced several times over the lifetime of the fixtures adding to the total lifetime cost of the light.

\section{REFERENCES}

[1] Daniel F. Butay, Michael T. Miller. "Maximum Peak Power Tracker: A Solar Application" April 24th, 2008.

[2] Wang Yongqing. "Design of Solar LED Street Lamp Automatic Control Circuit". NationalTestingCenterofIron\&Steel.2009

[3] "Lab 1 - Electrical Characteristics of Photovoltaic Cells " School of Electrical and Information Engineering, University of Sydney.Semester2,2011.

[4] Pan Shiquan "Application Research in the Solar Street Lamp Management Based on the LED Lightemitting Diodes" Bulletin of Science and Technology, Vol.28 No.4 Apr.2012.

[5] P. Tenti. "Dispense del Corso di Elettronica Industriale". Università degli Studi di Padova.2012.

[6] Malik Sameeullah, Jamia Millia Islamia," Implementation of automatic solar street light control circuit", International Conference on Energy and Environment Technology,2012.

[7] T. Esram. "Comparison of Photovoltaic Array Maximum Power Point Tracking Techniques" Energy Conversion, IEEE Transactions on (Volume:22Issue:2) 2007.

[8] A.Somasekhar, B.Umakanth, "An Intelligent Lightening System for Power Saving Applications", International Journal of Engineering Trends and Technology (IJETT). Volume 13 Number 1 - Jul 2014. ISSN: 2231-5381.

[9] Sharath Patil G.S, Rudresh S. M, Kallendrachari. K. Vani. H.V, "Design and Implementation of Automatic Street Light Control Using Sensors and Solar Panel," International Journal of Engineeing Research and Applications, vol. 5, no. 6, pp. 97-100, June 2015.

[10] Https://en.wikipedia.org/wiki/Solar_street_light 